\title{
Programa de capacitação de famílias de crianças, jovens e adultos usuários de comunicação alternativa
}

\section{Training program for families of alternative communication users}

\begin{abstract}
Resumo: Este trabalho teve como objetivo inserir um programa de capacitação de familiares de crianças, jovens e adultos usuários de sistemas suplementares e alternativos de comunicação no contexto das linguagens alternativas. Participaram deste estudo famílias na faixa etária de 25 a 65 anos no período de 2010 a 2012. As atividades foram realizadas semanalmente com a duração de uma hora em um laboratório de comunicação alternativa. Todas as atividades foram filmadas e, após a transcrição dos relatos verbais dos participantes. As categorias obtidas foram analisadas de acordo com as etapas do programa. Os resultados indicaram que as famílias perceberam: a necessidade do uso dos sistemas gráficos para a comunicação, importância da adaptação dos materiais e a necessidade de perceber as diferentes habilidades de seus filhos. O trabalho reforçou a necessidade de orientação sistemática e contínua para as famílias, assim como, destacou o uso dos sistemas gráficos no contexto da linguagem.

Palavras-chave: Educação especial. Inclusão. Família. Habilidades comunicativas. Comunicação alternativa.
\end{abstract}

\begin{abstract}
This study aimed to enter a training program for family members of children, youth and adults who use augmentative and alternative communication systems in the context of alternative languages. The study included families in the age group of 25-65 years in the period 20102012. The activities were held weekly with duration of one hour in a alternative communication laboratory. All activities were videotaped and after that, the verbal participants' reports were transcribed. The obtained categories were analyzed according to the steps of the program. The results indicated that families realized: the necessity of graphics systems for communication; the importance of adapted materials; and the need to understand their children's different skills. The study reinforced the need for systematic and continuous guidance for families, as well as highlighted the use of graphics systems in the context of language.

Keywords: Special education. Inclusion. Family. Communication skills. Alternative communication
\end{abstract}

DELIBERATO, Débora; MASSARO, Munique; GOLDONI, Natálie; SILVEIRA, Julia M. V. Programa de capacitação de famílias de crianças, jovens e adultos usuários de comunicação alternativa. Informática na Educação: teoria e prática, Porto Alegre, v. 16, n. 2, p. 89-103, jul./dez. 2013.

\author{
Débora Deliberato \\ Munique Massaro \\ Natálie Goldoni \\ Julia M. V. Silveira \\ Universidade Estadual Paulista
}

\section{Introdução}

D esquisadores da área da educação especial têm utilizado instrumentos da tecnologia assistiva para favorecer as pessoas com deficiência oportunidades de demonstrar suas reais habilidades e aprender novos conhecimentos (SORO-CAMATS, 2003; MANZINI; DELIBERATO, 2010). Rocha (2013) discutiu, na sua pesquisa de doutorado, que a tecnologia assitiva promove a pessoa com deficiência maior possibilidade de participação na rotina de suas atividades, porque possibilita a ampliação da funcionalidade nas diferentes tarefas.

A área da comunicação suplementar e alternativa é um instrumento que permite a uma parcela da população a garantia ao acesso à 
comunicação humana (NUNES, 2003; DELIBERATO, 2007, 2012). Atribui-se à Comunicação Alternativa o mérito de dar voz as pessoas com deficiência e que não tem a possibilidade de falar, promovendo que os mesmos possam expressar suas necessidades, sentimentos e pensamentos de forma mais clara (von TETZCHNER; MARTINSEN, 2000; NUNES, 2001; ALVES, 2006).

Alves (2006) descreveu nos resultados de sua pesquisa que o interlocutor que estabelece a interação com as pessoas com deficiência e sem o uso fala deve ser capacitado no contexto das diferentes habilidades comunicativas, ou seja, no contexto das linguagens alternativas. Desta forma, espera-se que os interlocutores falantes possam compreender o universo das pessoas com deficiência e, assim, contribuir para sua inserção social.

Neste contexto Nunes (2003) destacou que:

[...] o interlocutor acaba exercendo um papel ativo na interação com os não falantes, que seja quando está falando ou ouvindo. $\mathrm{O}$ sucesso no processo de comunicação de usuários de comunicação alternativa depende muito das estratégias utilizadas pelos diferentes interlocutores e também do seu grau de competência, melhorando assim, as habilidades comunicativas dos usuários (NUNES, 2003, p. 17-24).

Soro-Camats (2003) e Deliberato (2012) discutiram que durante uma situação dialógica entre um usuário de sistema gráfico e uma pessoa falante podem ocorrer duas situações, ou seja, o interlocutor falante pode iniciar e orientar certa conversa por meio de estratégias simples, limitando a conversa a determinado tema de interesse do usuário para facilitar a participação do mesmo na situação dialógica. Por outro lado, os autores discutiram que os interlocutores falantes podem subestimar a capacidade do usuário de sistemas gráficos e, com isto, dificultar a participação dos mesmos nas situações interativas. Nesta situação, seria possível perceber que o interlocutor falante assume a vez, ou melhor, a voz da pessoa com deficiência.

A situação acima descrita pode ser observada quando o interlocutor que não possui experiência ou vivência com pessoas com deficiência e usuárias das linguagens alternativas. Neste caso o interlocutor falante pode adotar uma conduta de superioridade e não leva em conta o que o usuário sabe e consegue entender. Assim a comunicação dos mesmos consiste predominantemente em responder, e ainda, o interlocutor pode limitar até as resposta (von TETZCHNER; MARTINSEN, 2000).

Assim a literatura tem discutido e pesquisado a necessidade do treinamento de parceiros comunicativos competentes no uso das linguagens alternativas para que o sucesso na aplicação da comunicação alternativa, bem como a interação, possa transcorrer de forma satisfatória. Os pesquisadores e profissionais da área, também, argumentaram que os interlocutores falantes mais competentes podem ser pessoas que já apresentam vínculo com o usuário, garantindo que o aprendizado das linguagens alternativas ocorra nos contextos funcionais (STUART; BEUKELMAN; KING, 1997; DELIBERATO; MANZINI, 2012).

Deliberato, Manzini e Guarda (2004) afirmaram e alertaram a necessidade de capacitar os profissionais, professores e educadores no contexto da comunicação suplementar e alternativa para que os usuários das linguagens alternativas possam ter um suporte favorável não somente durante os procedimentos de reabilitação, mas também, nos ambientes naturais.

Discutir a respeito dos recursos de comunicação suplementar e alternativa é pensar não 
somente nas habilidades e necessidades das pessoas com deficiências, mas em instrumentalizar os interlocutores, adequar os ambientes e as atividades e/ou tarefas a serem desenvolvidas pelas crianças e jovens com deficiência, sem a possibilidade de utilizar a linguagem falada como veículo de comunicação.

Neste contexto de discussão, a literatura da área aponta a família como núcleo central, no qual deve ser trabalhado o desenvolvimento do processo de implementação da comunicação alternativa, pois é com ela que a criança estabelece as primeiras formas de comunicação. Porém nem sempre é fácil e estimulador para os profissionais da área da saúde e educação trabalhar com as famílias, pois a introdução de sistemas alternativos de comunicação pode provocar mudanças na dinâmica interacional da família.

Para algumas crianças e jovens com deficiência e usuários de sistemas suplementares e alternativos de comunicação isso se torna ainda um desafio. Porém, a família dessas crianças e jovens são figuras centrais para a busca desse ideal, sendo parceiros importantes na intervenção, pois "as crianças não se tornarão usuários competentes de signos gestuais, gráficos e tangíveis sem que os membros da família compreendam e apoiem esse esforço" (VON TETZCHNER; MARTISEN, 2000).

Isso se aprofunda na ideia de que as famílias devem ser ensinadas a utilizar formas de comunicação suplementar e alternativa para, transformar as atividades de rotina dessas crianças e jovens com deficiência tão agradável, variadas e interessantes quanto possíveis, pois, a família é norteadora para o desenvolvimento da linguagem e consequente eficácia comunicativa de seu filho (VAN RIPER; EMERICK, 1997).

A importância da família no desenvolvimento da comunicação de crianças e jovens usuá- rios de comunicação suplementar e alternativa são de tamanha importância, pois, a família é o primeiro parceiro comunicativo dessas crianças e jovens. É a família que irá promover as possibilidades de interação social, a apresentação de modelos comunicativos e respostas aos esforços contínuos de comunicação dessas crianças e jovens (ANGELO, 2000).

Borges e Salomão (2003) também salientaram que a família é um contexto de socialização muito relevante para criança e jovens usuários de comunicação suplementar e alternativa, já que por vários anos foi em muitos momentos o único, bem como, o principal meio que favoreceu o crescimento do funcionamento da interação dessas crianças e jovens com outros contextos. São os pais que possibilitam os contatos sociais da criança com pessoas que não fazem parte da família.

Desta forma, crianças e jovens com deficiência e usuários de sistemas suplementares e alternativos de comunicação podem depender exclusivamente de seu contexto familiar para viabilizar a aquisição e o desenvolvimento da linguagem, bem como, proporcionar oportunidades de desenvolvimento e interação social.

No entanto, a participação da família não se restringe apenas a esse processo. Conforme referiram Angelo (2000) e von Tetzchner e Martinsen (2000) é necessário que a família aprenda a utilizar o sistema de comunicação alternativa que sua criança ou jovem faça uso para que seja acionada a integração dos recurso de comunicação alternativa em ambiente familiar e na comunidade.

A família poderia ser um ambiente importante para favorecer o suporte necessário para as crianças e jovens com deficiência no uso dos sistemas suplementares e alternativos de comunicação (DELIBERATO; MANZINI, 2012, DELIBERATO, 2013).

A literatura da área tem discutido que é um 
desafio sistematizar programas de intervenção baseados em sistemas de comunicação suplementar e alternativa, frente à diversidade de pessoas com deficiências que necessitam de instrumentos para a comunicação. A mesma literatura também tem ponderado que é um desafio maior inserir os sistemas de comunicação suplementar e alternativo nos diferentes ambientes para ampliar as possibilidades comunicativas e garantir meios para desenvolver interlocutores competentes no uso dos sistemas de representação não empregados na comunidade (DELIBERATO, 2012, 2013).

Nesta direção Soto e Glennen (1997) apontaram em seus estudos alguns aspectos com relação à interação entre mães e crianças usuárias de recursos alternativos de comunicação, e destacaram que a maioria das crianças quando na presença de suas mães, o uso do recurso alternativo de comunicação é diminuído. Tal fato, segundo as autoras, estaria ligado à relação muito próxima que as mães possuem com os filhos, permitindo que os mesmos sejam compreendidos sem grandes dificuldades.

Ainda nessa direção Jack et al. (1996) identificaram em uma de suas pesquisas que quanto maior o grau de intimidade entre interlocutor e usuário de recurso alternativo e suplementar de comunicação, menor é o uso do recurso alternativo e suplementar de comunicação, pois o vínculo estabelecido proporciona uma maior entendimento.

Os resultados da pesquisa de Alves (2006) também foram semelhantes aos resultados de Soto e Glennen (1997) e Jack et al. (1996), ou seja, o aluno com paralisia cerebral e usuário de recursos de comunicação alternativa necessitou de maior apoio do sistema gráfico com interlocutores desconhecidos do que com os interlocutores conhecidos, como no caso da mãe e da professora. Nas situações observadas na presença da mãe e da professora, o jovem com deficiência preferiu utilizar das habilidades não verbais e não orais como os gestos, expressões faciais, o olhar e das habilidades não verbais e orais, como no caso das vocalizações com entonações.

Estes estudos reforçam a necessidade $e$ importância de trabalhos e pesquisas direcionadas a programas de capacitação de interlocutores.

\section{Objetivo}

Este trabalho teve como objetivo inserir um programa de capacitação de familiares de crianças, jovens e adultos usuários de sistemas suplementares e alternativos de comunicação no contexto das linguagens alternativas.

\section{Desenvolvimento do estudo}

Este estudo faz parte de uma pesquisa maior Implementação de recursos de Comunicação suplementar e alternativa no contexto escolar e familiar aprovada pelo comitê de ética no $1202 / 2006$. O estudo maior teve início no ano de 2007, mas foram selecionadas as filmagens entre os anos de 2010 a 2012 dos grupos das famílias de crianças, jovens e adultos.

\section{Participantes}

Foram selecionados e formados durante o período estabelecido cinco grupos de famílias de crianças e jovens usuários de sistemas gráficos perante o critério de idade das crianças, jovens assistidos pelos setores da fonoaudiologia, fisioterapia, terapia ocupacional e peda- 
gogia durante março de 2010 a dezembro de 2012.

Sendo assim durante os dois anos de trabalho os grupos variaram de participantes entre dois a cinco em cada grupo, totalizando 25 participantes na faixa etária de 25 a 65 anos. Os grupos foram estabelecidos por meio da idade dos usuários dos sistemas gráficos: Grupo 1 e Grupo 2: família de crianças de dois a sete anos. O grupo 1 funcionou no período da manhã e o Grupo 2 no período da Tarde. Grupo 3 e Grupo 4: família de crianças e jovens entre oito a 17anos. O grupo 3 funcionou no período da manhã e o grupo 4 no período da tarde. Grupo 5: família de jovens e adultos a partir de 18 anos. Este último grupo funciona somente no período da manhã.

\section{Procedimentos}

As atividades foram realizadas semanalmente em um centro especializado no atendimento na área da saúde e educação de uma cidade do interior de São Paulo. As famílias foram convidadas a participar de uma oficina de orientação a respeito de comunicação suplementar e alternativa no momento do atendimento na área da fonoaudiologia. A Oficina foi realizada por meio das ações previstas pelo Laboratório de Comunicação Alternativa do Centro especializado no atendimento na área da saúde e educação.

Cabe destacar que as crianças e jovens foram atendidos pelo setor de fonoaudiologia duas vezes por semana, sendo que, uma vez na semana a família participava de oficina de orientação e, no segundo atendimento, a mesma participava das atividades feitas durante os atendimentos do setor da fonoaudiologia.

$\mathrm{Na}$ oficina de orientação a respeito da comunicação alternativa foram propostas as eta- pas do programa de orientação de Deliberato e Silveira (2009):

1. Identificação das necessidades do grupo: foram identificadas as rotinas dos familiares e as expectativas da participação no grupo. Neste momento foram realizadas dinâmicas com o grupo e destacadas as necessidades a respeito dos aspectos de comunicação nas situações da rotina de atividades.

2. Orientações a respeito: linguagem, habilidades comunicativas: após a identificação das necessidades a respeito das habilidades de comunicação, os profissionais realizaram orientações a respeito do desenvolvimento da linguagem, habilidades de comunicação no momento da realização da confecção dos materiais necessários aos usuários de sistemas de comunicação alternativa.

3. Conceitos e vivências com a Comunicação Alternativa: foram apresentados os conceitos a respeito das linguagens alternativas, os sistemas mais utilizados e os recursos já confeccionados por outros familiares.

4. Atividades práticas vinculadas aos atendimentos dos clientes: durante as orientações a respeito dos recursos de comunicação alternativa, os familiares foram orientados a respeito das atividades realizadas nos atendimentos terapêuticos e, também foram discutidas as necessidades de recursos na escola.

5. Contato com materiais: os familiares vivenciaram os recursos utilizados com as crianças e jovens nas situações de rotina de vida diária.

6. Dinâmicas com materiais: após a Vicência com os recursos, os familiares utilizaram os mesmos nas situações da rotina familiar. 
7. Identificação das necessidades de comunicação: durante o processo de vivência com os materiais, as famílias identificaram as necessidades de comunicação das crianças, jovens e adultos com deficiência.

8. Seleção de vocabulário: durante as orientações e vivências com os diferentes materiais, os familiares selecionaram os conteúdos necessários para serem utilizados na rotina familiar.

9. Elaboração de materiais: no momento da elaboração do material, os familiares foram envolvidos com os conteúdos teóricos a respeito da importância do uso dos sistemas suplementares e alternativos de comunicação na situação natural.

10. Utilização dos materiais: à medida que os familiares produziram os recursos, os mesmos foram utilizados no processo terapêutico, na escola ou em situação sociais.

11. Relato das experiências: durante as atividades realizadas no grupo as experiências foram relatadas a novos familiares.

As atividades realizadas nas diferentes etapas do programa foram organizadas e aplicadas no Laboratório de Comunicação Alternativa por um grupo de profissionais da área da saúde e educação: fonoaudiologia, pedagogia, terapia ocupacional e do serviço social. Na área da psicologia os familiares foram orientados e assessorados a respeito das condições necessárias para a aceitação e uso dos diferentes recursos necessários para ampliar e inserir habilidades comunicativas. Sendo assim, o setor de psicologia oferecia apoio aos mesmos grupos quinzenalmente.

\subsection{Instrumentos de registro e ma- teriais de coleta}

Todas as atividades foram filmadas e fotografadas para serem analisadas seguindo o objetivo proposto. A filmagem é uma técnica capaz de permitir o registro de procedimentos de pesquisa, uma vez que garante ao pesquisador a possibilidade de rever as situações quantas vezes forem necessárias, favorecendo a adequada análise dos dados coletados (PINHEIRO; KAKEHASHI; ANGELO, 2005).

Durante as atividades foram utilizados materiais como: software Boardmaker (JOHNSON, 2004); cartolinas, colas, plásticos, fotos, figuras, materiais concretos, livros infantis, plastificadora, feltro, panos coloridos entre outros materiais necessários para a confecção dos recursos necessários para os usuários de sistemas suplementares e alternativos de comunicação.

\subsection{Procedimentos de análise dos dados}

Após assistir as fitas e extrair os trechos de filmagens que pudessem representar as etapas do programa, os registros dos relatos verbais obtidos foram ouvidos e assistidos duas vezes pela pesquisadora e transcritos na íntegra. Ainda, foram realizados ajustes ortográficos dos relatos verbais dos participantes da oficina. Para contemplar a organização desses relatos transcritos foi realizado um protocolo para organização dos dados com os seguintes itens: data da fita; descrição do ambiente: tarefas propostas; procedimentos realizados e os resultados. 


\section{Resultados e discussões}

Em função da quantidade de informações obtidas por meio das transcrições dos relatos verbais nos cinco grupos trabalhados, neste trabalho serão apresentados exemplos de dois grupos: Grupo 1 e Grupo 3. Sendo assim, os exemplos estão direcionados às famílias de crianças e jovens com deficiência e sem a possibilidade de utilizar a fala nas situações de interação e comunicação.

A literatura tem discutido a importância da capacitação de interlocutores no contexto das linguagens alternativas. Inserir a família, professores e demais interlocutores no contexto da comunicação alternativa poderia favorecer modelos de estruturas linguísticas importantes para o usuário de sistemas gráficos nas situações naturais (LIGHT, 2003; VON TETZCHNER et al., 2005; ALVES, 2006; DELIBERATO; MANZINI, 2012).

Neste contexto de discussão, os autores pontuaram a necessidades de programas de capacitação de interlocutores, especialmente os interlocutores do contexto familiar. O exemplo a seguir ilustra metas das etapas $1 \mathrm{e}$ 2 do programa de orientação proposto:

\section{Fita I - 04/05/2010}

Dinâmica com as famílias e vivência com o conceito das linguagens alternativas: Etapa 1 e 2 do programa proposto.

Descrição do Ambiente: a atividade foi realizada em uma sala do Laboratório de Comunicação Alternativa. Na sala estavam presentes cinco mães do grupo 2 (M1, M2, M3, M4 e M5) e três terapeutas (T1, T2, T3: duas fonoaudiólogas e uma terapeuta ocupacional). Recursos de baixa e alta tecnologia estavam dispostos em uma mesa para todas as mães. Nas descrições entre parênteses estão as descrições dos comportamentos observados durante as atividades.

Procedimentos: Inicialmente as mães se apresentaram e relataram a respeito dos seus filhos, principalmente as dificuldades. Em seguida, as mães escolheram cada uma delas uma notícia de jornal. Após a escolha, as mães estariam transmitindo o conteúdo da notícia selecionada, por meio dos recursos de comunicação alternativa disponível, ou seja, elas apresentaram o conteúdo sem utilizar a fala.

Orientação para o início da atividade:

T1: Vocês podem representar o material por gesto, por desenho ou papel. Vocês estão vendo o material na mesa (vira para a mãe que está na mesa). Pode ficar a vontade em utilizar o que está na mesa, e em seguida ela mostra: têm figuras, letras, números, vários objetos. Vejam o que vocês conseguem para transmitir o conteúdo que está na notícia.

M1: olha a mesa, pega uma das caixas com as figuras e as observa frente e trás.

M1: Mas ainda não pega né?

T1: Pode pegar. Pode.

T2: Tem umas figuras que tem velcro. Você pode pegar e colar nessa plaquinha (aponta para a prancha com velcro). Isso para facilitar para você por.

T1: É (aponta para a prancha).

M1: (Faz que sim com a cabeça).

M1: (Continua olhando as figuras).

M1: (Seleciona algumas figuras e olha para a prancha apontada).

T1: Vai precisar M1? (risos)

M1 e M1: risos.

M1: Desenhar pode?

T1: Pode desenhar também e usar todos os materiais que têm ai. Pode usar gestos... e eu vou tentar descobrir.

M1: (está procurando figuras em diferentes caixas e a mesma vai colando com velcro as figuras na prancha).

M1: Pode fazer desenho né?

T1: Pode ser.

T2: Ou pode desenhar agora para você já 
mostrar o desenho para o outro né!

M1: (mãe levanta, acha um apoio e consegue desenhar)

Deliberato e Manzini (2012) descreveram a necessidade dos pais e demais interlocutores da família estarem atentos as habilidades de seus filhos e ao conteúdo necessário para que os mesmos possam se comunicar. O exemplo demostra a necessidade de o profissional instruir e esclarecer as famílias que é possível ocorrer a interação e comunicação por meio de outras habilidades. Nesta situação, o profissional deve participar e envolver os interlocutores na situação, procurando alertar a respeito dos instrumentos.

A instrução inicial e processual deve ocorrer durante todo o momento de capacitação das famílias. Neste sentido, o exemplo a seguir pontua a atuação do profissional no momento das famílias praticarem o uso dos recursos de comunicação alternativa:

T1: Mas você leu a reportagem?

M2: Ai... estou vendo só o desenho só

T1: Não.

M2: Só... para ter uma ideia assim...

T1: Não, lê a reportagem que esclarecer mais para você

M2: É.

T2: É, transmiti mais a reportagem.

M2: As falas tem que ter isso daqui (Aponta para a reportagem de jornal)

T1: É.

M2: Tenho que ler isso aqui ou só olho o desenho e pronto?

T1: Ó, na verdade é assim, é uma reportagem então não vai dar/acho que talvez pegar todos os detalhes para estar passando, mas tenta o máximo que você conseguir passar a mensagem da reportagem.

T2: A ideia central da reportagem.

T1: É.

T2: É importante saber do que trata a reportagem. O que é que está falando, se ela é importante para alguma coisa.

M1: A sim... é, ai eu tenho que ler né? (ler a reportagem) (risos)

T1: É, é bom você ler (risos)

A orientação permitiu esclarecer que a pessoa que estabece a interação com os usuários de sistemas suplementares e alternativos de comunicação deve se envolver nos conteúdos e utilizar os diferentes materiais para oferecer um modelo linguístico mais adequado (LIGHT, 2003; BEUKELMAN; MIRENDA, 2007). Alves (2006) discutiu que o uso dos sistemas gráficos pode estar relacionado com o grau de intimidade que o interlocutor tem com o usuário de comunicação alternativa, ou seja, quanto maior o conhecimento que a família tem de seu filho, menos acesso ele faz ao recurso de comunicação.

A seguir estão os exemplos de três mães realizaram após as orientações:

M1: (Levanta e vai até a frente de todas as mães expor o que ela conseguiu representar por meio dos recursos de comunicação alternativa). (Apresenta uma folha com um desenho de um prédio).

M3: prédio?

M1: (Sim com a cabeça).

M1: (Apresenta uma figura de uma pessoa com alguma expressão facial).

M2: Preocupação?

M1: (Sim com a cabeça).

T1: As pessoas estavam preocupadas.

M1: (Apresenta nova figura)

M2: Quente?

T1: sol quente?

M1: (não com a cabeça).

M1: (mostra uma imagem desenhada por ela como uma fogueira). Sim, fogo é quente. As pessoas estavam saindo correndo preocupadas por causa do fogo do prédio.

T1: O que era?

M1: incêndio do prédio

T1: Está certo. 
M1: Funcionários saindo correndo. A pergunta é incêndio. Edifício pegando fogo.

T1: Foi fácil (risos)

M1: foi rápido até!

T1: aham, foi.

T1: Você utilizou o desenho, mas também usou as figuras figuras

M2 e M3: É.

M1: o prédio e o fogo.

M2: e a turma correndo.

M1: pessoas preocupadas.

T1: e o quente né?

M1: o quente.

T1: ai que é importante a figura, está representando exatamente o que quer dizer. Esse quente está com o calor do sol então daí quando a gente for representar, por exemplo, por causa do fogo, ai a gente representaria de uma outra forma esse quente. Mas o quente já da para gente ter ideia para generalizar que o quente ali, na situação das pessoas saíram correndo: então está pegando fogo M1: Legal. Consegui entender

Por meio do exemplo da M1 foi possível identificar a importância do uso das imagens: desenho feito por ela e a figura associado aos movimentos de cabeça em respostas as perguntas feitas. Knap e Hall (1999) discutiram a importância da comunicação não verbal na interação humana e, os mesmos autores alertaram a respeito do uso das diferentes modalidades de expressão em busca de uma maior competência na comunicação. A combinação das habilidades de M1 permitiu aos interlocutores acesso ao entendimento de sua mensagem.

A falta do uso das diferentes modalidades expressivas para manter a interação e a comunicação pode acarretar a falta do entendimento da mensagem e, desta forma, o interlocutor falante acaba desistindo na construção de sua intencionalidade por meio de outros instrumentos e expressa a mensagem somente por meio da fala. Desta forma, o interlocutor falante não oferece um modelo para o interlo- cutor não oralizado, como pode ser observado a seguir:

M2: (risos) Ó achei um (coloca mão na boca) (risos)

T1: EU

M2: (faz gesto)

M1: tomando banho?

M3: chuva?

M2: (faz gestos e aponta figura de um transporte).

M2: (aponta para um transporte e indicou a figura que representa pessoa)

T1: É isso.

Em seguida M2 acaba falando o que tinha na reportagem:

M2: Foi muita chuva nesse lugar e teve chuva, caiu casa, teve muito sofrimento das pessoas, choraram e os carros bateram um no outro também. Estava escuro na hora da chuva, muita chuva e muito sofrimento, então... (risos)

T1: É a M2 mostrou só um pedacinho da reportagem, é, mas não deu para entender que foi esse pedacinho que você contou né.

M2: É teve batidas também né, na hora que eu fiz assim né (gesto de bater duas figuras que tinham a imagem de carros) um carro bateu na casa.

T1: É.

M2: acidente.

T1: ahãm.

É isso.

A oficina de orientações a respeito da comunicação alternativa tem como meta a imersão das famílias no contexto da comunicação alternativa. Neste sentido, a presença de mães, pais e outros cuidadores com diferentes percepções e atitudes frente a comunicação podem favorecer a discussão e entendimento da função dos sistemas gráficos para a comunicação. O exemplo a seguir, reforça a diversidade e uso das modalidades de expressão entre as mães e possibilita a troca de informações entre os participantes do grupo: 
M3: Vai a frente da turma de mães e terapeutas para fazer sua expressão da notícia escolhida utilizando os recursos de comunicação alternativa. Ela expressou por meio de gestos e figuras a situação de um final de semana.

T1: A gente percebe que a M3 usou gestos para estar representando. Algumas vezes são fáceis para agente entender o conteúdo por meio dos gestos. O ovo né, geralmente é fácil, então é fazer assim (gesto do ovo) dentro do contexto a manteiga (gesto da manteiga) é fácil compreender, mas pode ter gestos que são difíceis e com a figura ficou mais fácil de compreender o que é, mostrando os passos do que aconteceu exatamente no final de semana. É foi bem fácil de entender com as figuras.

\section{1/06/2011}

Confecção de material: etapa 7 e etapa 9 do programa

Ambiente: A atividade foi realizada na sala do Laboratório de Comunicação Alternativa. Estavam presentes na oficina duas fonoaudiólogas (T1 e T2) e uma mãe do Grupo 2 (M1). Os materiais utilizados na oficina foram figuras impressas por meio do programa Boardmaker (JOHNSON, 2004), além da utilização de EVA, tesoura e papel contact entre outros materiais.

Procedimentos: a proposta foi realizar a confecção de um jogo com letras e figuras para uma criança com paralisia cerebral, filha de outra mãe que participa na oficina, mas neste dia estava ausente. A criança apresentava dificuldades em manipular objetos. Portanto, na oficina foi confeccionado o material em EVA grosso para ser utilizado e avaliado na situação da terapia.

T1: Mas para a M. terá que adaptar. M1: É.

T1: Ah! E tem o B. também.

M1: o B.

T2: É.
M1: Isso que eu ia falar.

T2: O B. também precisa desse material para usar o jogo.

M1: Eu achei que você não tinha mencionado por causa de alguma adaptação.

T1: É mas é... Para o B. não vai poder ser assim, vai ter que ser de outra maneira.

T2: Uhum, tem que ser mais grosso, tem que ser com isopor ou EVA grosso

T1: É então a gente, á M2 estava ajudando a gente a pensar e fazer o material.

M1: É de madeira?

T1: A gente já tinha discutido que para ele tinha que ser de madeira.

M1: Aham.

T1: Pra ele tinha que mudar.

M1: É isopor mesmo que é mais barato (sorriu), mas não serve para ele.

Braccilli (2008) e Rocha (2013) discutiram a necessidade da adequação dos recursos pedagógicos e da comunicação alternativa frente as habilidades motoras, sensoriais, perceptivas, cognitivas e linguísticas de cada criança ou jovem com deficiência. Os atributos dos recursos devem oferecer aos usuários de sistemas gráficos o domínio operacional para que os mesmos possam proporcionar ao usuário independência e funcionalidade (LIGHT, 2003).

O exemplo a seguir, também, ilustra a atitude das mães frente a necessidade de adaptação de um recurso:

Descrição do ambiente: Nessa oficina três mães se organizaram para confecção de materiais, no caso a confecção foi de um painel de aniversário, o material disponível foi computador e software Boardmaker. Assim, as mães estavam discutindo o tamanho das figuras que iriam montar o painel de aniversário, sendo que uma das mães tem um filho com baixa visão. Os participantes da oficina foram: três mães do grupo 2 ( $M 1, M 2, M 3$ ) e duas terapeutas (T3; T4): terapeuta ocupacional e uma pedagoga. 
T3: Mas o que questionaram também na oficina da manhã foi o tamanho de $(1,5 \mathrm{~cm})$ será que não é muito pequeninho para esse tamanho (aponta para figura proposta para o painel) que eu estou pensando?

M1: Esse né (aponta para a figura)

T3: É para criança ver (Tom de interrogação). Porque não vai ser só vocês que vão estar lá, vai ter o nome das crianças para as crianças identificarem. AH HOJE, É meu aniversário: vai estar lá no painel. Meu nome é...

M1: É, ai para a criança já é pequenininho, temos que modificar.

Deliberato (2010, 2011, 2013) tem discutido amplamente a necessidade das famílias e professores estarem atentos a função da comunicação alternativa. Os interlocutores devem perceber que os recursos e as adaptações são importantes, mas há necessidade das famílias perceberem o vínculo dos sistemas gráficos com o desenvolvimento da linguagem.

Esta temática permeia as diferentes etapas do programa proposto: usar os sistemas gráficos na rotina de vida do usuário de sistemas gráficos de forma a ter maior funcionalidade. Entender a complexidade da linguagem e usar as diferentes modalidades de expressão pode ser um desafio, principalmente para as famílias que estão preocupadas com a fala. O exemplo a seguir ilustra uma mãe que tem um filho com severa alteração motora e da linguagem e, com o uso dos recursos de comunicação alternativa passou a oralizar palavras que podem ser entendidas no contexto:

\section{Fita 30 - 15/05/2012}

Discussões a respeito da Comunicação alternativa: etapa 2, 10 e 11

Ambiente: a Oficina foi realizada na sala do Laboratório de Comunicação Alternativa. Estavam presentes na oficina duas terapeutas (T1, T2) e três mães do Grupo 1 (M6, M7, M8).
Procedimentos: Foi o primeiro encontro do ano de 2012. Foi um momento de discussão e debates, em vista das mães já fazerem parte da oficina desde 2010. Portanto, foi um momento de retorno das atividades com proposta de discussões a respeito da Comunicação alternativa e o seu uso nos diferentes ambientes.

T1: vocês pensaram o que vocês acham que tem de dificuldade? Quais dificuldades vocês tem para se comunicar?

M6, M7 e M8: (se olharam e riram).

M6: Bom, o D. ele fala né, conversa, pede, então eu não sei.

T1: uhum.

M6: Mais na parte motora né... de... Coordenação.

T1: E você acha que os outros entendem o que ele fala. Assim né... Com outras pessoas que ele não fala rotineiramente, outra pessoa que não seja a senhora que conversa com ele também.

M6: Ah sim! Ele fala, pergunta né!

T1: É mais a parte motora então? Ou você vê assim.

M6:É porque ele não pega assim para escrever assim, não consegue né.

T1: Tipo os objetos.

M6: É, tudo né, até para comer você tem que pegar e ajudar ele.

T1: uhum.

M6: ele esquece e coloca na boca direto.

M6, M7, M8 e T1: (risos)

Por meio do exemplo é possível identificar que para a M6 a comunicação do filho de sete anos está boa, porque ele está oralizando, mesmo que sejam palavras ou frases simples. A mãe está preocupada com as questões motoras, cujo comportamento é mais observável e concreto.

Este fato pode acarretar o abandono do uso dos instrumentos de comunicação alternativa com o propósito de ampliar nas questões da linguagem. Light (2003) defendeu que para o 
desenvolvimento da linguagem dos usuários de sistemas gráficos o domínio operacional é fundamental, mas não o único necessário.

Sendo assim, um programa de capacitação no contexto da comunicação alternativa para as familiares de forma contínua e compartilhada pode contribuir para a inserção da família no contexto da complexidade da linguagem.

\section{Conclusões}

O programa permitiu ao longo das etapas que as famílias participassem de vivências com os sistemas gráficos e, também, possibilitou a confecção de materiais que foram utilizados nas intervenções dos setores da fonoaudiologia, nos ambientes da família e da escola. O trabalho realizado tem permitido reforçar a necessidade de orientação sistemática e contínua com as famílias de crianças, jovens e adultos usuários de sistemas gráficos, assim como, reforçou a necessidade da participação de uma equipe multidisciplinar.

\section{Referências}

ALMIRALL, C. B.; SORO-CAMATS, E.; BULTÓ, C. R. Sistemas de sinais e ajudas técnicas para a comunicação alternativa e a escrita: princípios teóricos e aplicações. São Paulo: Livraria Santos Editora, 2003.

ANGELO, D. Impact of augmentative and alternative communication devices on families. Augmentative and Alternative Communication, Vancouver, v. 16, n.1, p. 37-47, 2000.

ALVES, V. A. Análise das modalidades expressivas de um aluno não falante frente a diferentes interlocutores durante a situação de jogo. 2006. 169 f. Dissertação (Mestrado em Educação) - Faculdade de Filosofia e Ciências, Universidade Estadual Paulista, Marília, 2006.

BEUKELMAN, D. R.; MIRENDA, P. Augmentative \& alternative communication: supporting children \& adults with complex communication needs. Baltimore: Paul H. Brookes Publishing Co, 2007.

BORGES, L. C.; SALOMÃO, N. M. R. Aquisição da Linguagem: Considerações da perspectiva da interação social. Psicologia: Reflexão e Crítica, v. 16(2), p. 327-36, 2003.

BRACCIALLI, L. M. P, et. al. Influência do assento da cadeira adaptada na execução de uma tarefa de manuseio. Rev. Bras. Educ. Espec., Marília, v.14, n.1, p.141-154, 2008.

DELIBERATO, D. Comunicação alternativa na escola: possibilidades para o ensino do aluno com deficiência. In: ZABOROSKI, A. P.; Oliveira. J. P. (Org.). Atuação da Fonoaudiologia na escola: reflexões e práticas. 1ed. Rio de Janeiro: WAK Editora, 2013, v.1, p. 71-90. 
Terminologias e aspectos teóricos das habilidades expressivas no contexto da comunicação alternativa In: Dimensões pedagógicas nas práticas de inclusão escolar. 1. ed. Marília: $A B P E E$, 2012, v.2, p. 385-97.

Sistemas suplementares e alternativos de comunicação nas habilidades expressivas de um aluno com paralisia cerebral. Revista Brasileira de Educação Especial, v.17, p.225-44, 2011.

Acessibilidade comunicativa no contexto acadêmico. In: MANZINI, E. J. (Org.) Inclusão do aluno com deficiência na escola: os desafios continuam. Marília: ABPEE, 2007, p. 25-36.

DELIBERATO, D.; MANZINI, E. J. . Identification of the Communicative Abilities of Brazilian Children With Cerebral Palsy in the Family Context. Communication Disorders Quarterly, v. 33, p. 195-201, 2012.

DELIBERATO, D.; SILVEIRA, J. Vicente da. Capacitação de famílias e cuidadores de crianças, jovens e adultos no contexto da comunicação alternativa. In: III Congresso Brasileiro de Comunicação Alternativa - ISAAC/Brasil, 2009, São Paulo. Anais... III CONGRESSO BRASILEIRO DE COMUNICAÇÃO ALTERNATIVA ISSAC/Brasil Qualquer forma de comunicar vale a pena, 2009, p. 1-1.

DELIBERATO, D. MANZINI, E. J. GUARDA, N. S. Implementação de recursos suplementares de comunicação: participação da família na descrição de comportamentos comunicativos dos filhos. In: Rev. Bras. Ed. Esp., Marília, Mai.-Ago. v. 10, n. 2, p. 217-40, 2004.

JACK, S. L.; SHORES, R. E.; DENNY, R. K.; GUNTER, P. L.; DeBRIERE, T.; DePAEPE, P. An analysis of the relationship of techer's reported use of classroom management strategies on types of classroom interactions. Journal of Behavioral Education, n. 6, p. 67-8. 1996.

JOHNSON, R. M. Boardmaker: The P.C.S. libraries on disk. Solana Beach: Mayer Johnson, 1994.

KNAPP, M. L.; HALL, J. A. Comunicação não-verbal na interação humana. São Paulo: JSN, 1999.

MANZINI, E. J.; DELIBERATO, D. Tecnologia assistiva: enfocando a educação. In: CAPELLINI, Vera Lúcia Messias; RODRIGUES, Olga Maria Piazentin Rolim. (Org.) Práticas pedagógicas inclusivas: da criatividade à valorização das diferenças. 1. ed. Bauru: UNESP/FC/MEC, 2010, v. 5, p. 183-219.

NUNES, L. R. O. P. Linguagem e comunicação alternativa: uma introdução. In: NUNES, L. R. O. (Org.). Favorecendo o desenvolvimento da comunicação em crianças e jovens com necessidades educacionais especiais. Rio de Janeiro: Dunya, 2003. p. 1-13. 
NUNES, L. R. d'O. de P. A comunicação alternativa para portadores de distúrbios da fala e da comunicação. In: MARQUEZINE; M.C.; ALMEIDA, M.A.; TANAKA, E. D. O. (Orgs.) Perspectivas multidisciplinares em Educação Especial II. Londrina: EDUEL, 2001.

PINHEIRO, E. M.; KAKEHASHI, T. Y.; ANGELO, M. O uso de filmagem em pesquisas qualitativas. Revista Latino-Americana de Enfermagem, Ribeirão Preto, v. 13, n. 5, p. 717-722, 2005.

ROCHA, A. N. D. C. Recursos e estratégias da tecnologia assistiva a partir do ensino colaborativo entre profissionais da saúde e da educação. 210 f. Tese (Doutorado) - Faculdade de Filosofia e Ciências, Universidade Estadual Paulista, Marília, 2013.

ROTHSCHILD, N.; NORRIS, L. Augmentative and alternative communication: management of severe communication disorders in children and adults. Brazil: Workshop, 2001.

SCHLOSSER, R; ROTHSCHILD, N. Augmentative and alternative communication for persons with developmental disabilities. Temas sobre desenvolvimento. Rio de Janeiro: Memnon, 2001, 10 (58/59), 6 CE-17CE.

SOTO, G; GLENNEN, S. L. Introduction to argumentative and alternative communication. In: GLENNEN S. L.; DE COSTE, D. C. (Ed) The handbook of argumentative and alternative communication. San Diego: Singular, 1997, p. 3-20.

STUART, S.; BEUKELMAN, D. R.; KING, J. Vocabulary use during extended conversations by two cohorts o f older adults. Augmentative and Alternative Communication, Washington, vol. 13, p.40-47, 1997.

VAN RIPER, C.; EMERICK, L. Correção da Linguagem: uma introdução à patologia da fala e à audiologia. Trad. Marcos Antônio Guirado Domingues. 8. ed. Porto Alegre: Artmed, 1997, 445p.

VON TETZCHNER, S.; MARTINSEN, H. Competências de conversação. In: . (Ed.). Introdução à comunicação aumentativa e alternativa. Porto: Porto Editora, 2000. p. 235-259. 
Submetido em 15 de agosto de 2013.

Aprovado em 04 de setembro de 2013.

Débora Deliberato - Universidade Estadual Paulista - Botucatu - SP - Brasil E-mail: delibera@marilia.unesp.br

Munique Massaro - Universidade Estadual Paulista - Botucatu - SP - Brasil E-mail: munique.massaro@gmail.com

Natálie Goldoni - Universidade Estadual Paulista - Botucatu - SP - Brasil E-mail: natalie.goldoni@gmail.com

Julia M. V. Silveira - Universidade Estadual Paulista - Botucatu - SP - Brasil E-mail: não informado 